\title{
Adaptation of vulnerable regional agricultural systems in Europe to climate change - results from the ADAGIO project
}

\author{
J. Eitzinger ${ }^{1}$, G. Kubu ${ }^{1}$, V. Alexandrov ${ }^{2}$, A. Utset $^{3}$, D. T. Mihailovic ${ }^{4}$, B. Lalic ${ }^{4}$, M. Trnka ${ }^{5}$, Z. Zalud ${ }^{5}$, \\ D. Semeradova ${ }^{5}$, D. Ventrella ${ }^{6}$, D. P. Anastasiou ${ }^{7}$, M. Medany ${ }^{8}$, S. Altaher ${ }^{8}$, J. Olejnik $^{9}$, J. Lesny $^{9}$, \\ N. Nemeshko ${ }^{10}$, M. Nikolaev $^{11}$, C. Simota ${ }^{12}$, and G. Cojocaru ${ }^{12}$ \\ ${ }^{1}$ Institute of Meteorology, University of Natural Resources and Applied Life Sciences (BOKU), Vienna, Austria \\ ${ }^{2}$ National Institute of Meteorology and Hydrology, Sofia, Bulgaria \\ ${ }^{3}$ Agrarian Technological Institute of Castilla and Leon (ITACYL), Valladolid, Spain \\ ${ }^{4}$ Center for Meteorology and Environmental Predictions (CMEP), Novi Sad, Serbia \\ ${ }^{5}$ Mendel University of Agriculture and Forestry in Brno (MZLU), Czech Republic \\ ${ }^{6}$ Instituto Sperimentale Agronomico (CRA-ISA), Italy \\ ${ }^{7}$ Inst. of Env. Research and Sustainable Development (IESRD-NOA), Greece \\ ${ }^{8}$ Central Laboratory for Agricultural Climate (CLAC), Egypt \\ ${ }^{9}$ August Cieszkowski Agriculture University of Poznan (ACAUP), Poland \\ ${ }^{10}$ State Hydrological Institute (SHI), St. Petersburg, Russia \\ ${ }^{11}$ Agrophysical Research Institute (ARI), St. Petersburg, Russia \\ ${ }^{12}$ TIAMASG Foundation, Romania
}

Received: 17 December 2008 - Revised: 21 January 2009 - Accepted: 30 January 2009 - Published: 21 October 2009

\begin{abstract}
During 2007-2009 the ADAGIO project (http://www.adagio-eu.org) is carried out to evaluate regional adaptation options in agriculture in most vulnerable European regions (mediterranean, central and eastern European regions). In this context a bottom-up approach is used beside the top-down approach of using scientific studies, involving regional experts and farmers in the evaluation of potential regional vulnerabilities and adaptation options. Preliminary results of the regional studies and gathered feedback from experts and farmers show in general that (increasing) drought and heat are the main factors having impact on agricultural vulnerability not only in the Mediterranean region, but also in the Central and southern Eastern European regions. Another important aspect is that the increasing risk of pest and diseases may play a more important role for agricultural vulnerability than assumed before, however, till now this field is only rarely investigated in Europe. Although dominating risks such as increasing drought and heat are similar in most regions, the vulnerabilities in the different regions are very much influenced by characteristics of the dominating agroecosystems and prevailing socio-economic conditions. This will be even be more significant for potential adaptation measures at the different levels, which have to reflect the regional conditions.
\end{abstract}

\section{Introduction}

Global climate change will lead to shifts in climate behaviour (IPCC, 2007a) and cause manifold impacts on ecosystems in the next decades (e.g. IPCC, 2007b). Through a change in climatic conditions and variability, for example, extreme

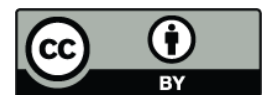

Correspondence to: J. Eitzinger

(josef.eitzinger@boku.ac.at) weather events (heat waves, droughts, etc.) are likely to occur more frequently in different spatial and time scales in future (e.g. Mearns et al., 1997; Rowell and Jones, 2005; Meehl and Tebaldi, 2004). Therefore, the assessment of climate change impacts on agroecosystem resources and functions (water, climatic stresses, soil and landscape functions) and potential adaptation measures at different spatial and time scales is indeed one of the most important issues in climate change research. 
An early recognition of risks and implementation of adaptation strategies is crucial as anticipatory and precautionary adaptation is more effective and less costly than forced, last minute, emergency adaptation or retrofitting (EEA, 2007). Results of climate change impact and adaptation studies often show considerable different results, depending on the spatial scale of regionalisation. However, for a decision maker, only a high spatial resolution of related study results is useful as it can represent local conditions and its spatial variability much better. A recent survey covering most European Union countries showed that the message about the climate change implications for agriculture or agroecosystems are still not reaching all farmers, extension service experts and governmental officials and if it does, it rarely leads to any concerted action (e.g. Orlandini et al., 2008). Detailed surveys in a number of countries within the ADAGIO project also pointed out that famers find the time horizons of 2050 or 2100 as difficult to imagine and the tools that are used by researchers as too "academic/theoretical". For the policy-makers it is not only the problem of time-scale but they also find presented results and methodologies as too complex and therefore unconvincing. However these stakeholders are well aware that the crop productivity of an individual region is, to a large extent, determined by variation in climate and soil conditions.

\section{Results}

Some key results presented here are based on surveys, researches (case studies) and questionnaires on regional vulnerability, impacts and adaptations of agriculture to climate change, carried out during the ADAGIO project (project duration 2007-2009; http://www.adagio-eu.org). In specific, the results combine feedbacks from local experts and farmers as well as results from simulation studies for both quantitative and qualitative assessments of climate change impacts and adaptation strategies.

\subsection{Mediterranean region}

The effects of temperature increment on shortening the crop cycle has been identified as a risk for all main crops. The yield variability associated to the more frequent heat waves and droughts has been also found as a Climate-change risk in the entire region, although it could be more dangerous for rainfed crops. Besides, the negative effects of new and changing pest and disease occurrence could be expected in Mediterranean agriculture. Specific remarks should be addressed to irrigated crops. Future water scarcity combined with the increment of the evaporative demand of the atmosphere could become unaffordable for still profitable agriculture. Farmers in irrigated lands might be in serious risk, while they could be not aware of this yet. Recent trends encourage water saving practices but are not still completely in- troduced. Hence, adaptation options are needed in Mediterranean irrigated agriculture more than in rainfed agriculture.

\subsection{Central European region}

The Central European region covers a wide range of climates, from cool and humid (e.g. alpine region) to warm an semi-arid/humid (most lowland areas) of the transition of continental to Atlantic and to Mediterranean type of climate. It also covers a wide and distinctive difference in farm structure and socio-economic conditions, mostly caused by the different historical socio-economic and political developments of the western (e.g. Austria, Italy) and eastern (e.g. Poland, Czech Republic) countries. Vulnerability of agroecosystems is affected by both conditions, even more their adaptive capacity. Although the Central European region is more humid compared to the Mediterranean region, drought (in combination with heat waves) is named in all countries as the main danger for agricultural production under climate scenarios, except in some mountainous and alpine regions. This assessment is of course based on the current regional production systems, mainly not adapted yet to severe drought and heat conditions (which is reverse compared to the Mediterranean area of already to drought and heat adapted production systems). Main arable crop production regions are affected by increasing drought conditions and water shortage during the summer period, leading to increased demand of water for irrigation. Permanent grasslands (in combination with dairy farming) in regions below app. $800 \mathrm{~mm}$ precipitation are most vulnerable to the warming trend, which comprise relatively large regions in Central Europe. Regions where a change to crop production or other alternatives is difficult due to terrain or soil conditions, will be probably the worst affected areas. However, there are big regional differences, caused not only by topographical effects on seasonal precipitation, but also by soil conditions regarding soil water storage capacity. Production of orchards and vineyards will be probably mostly affected by changed pest and disease occurrence. However, in some cases an increasing trend in frost danger or hail is named as well.

\subsection{Eastern European region}

In Eastern Europe all considered countries are facing negative climate change impacts and there are significant vulnerabilities as a result of extreme weather events such as drought, dry winds, wet spells, intensive precipitation, frosts, heat and cold waves, soil erosion and salinisation, decrease of crop growing period and occurrence of new pests and diseases. Whereas in the southern parts of Eastern Europe mainly summer crops are negatively affected by increasing summer drought and heat waves, in the more northern regions winter crops are especially affected by increasing water logging because of increasing precipitation during winter period and warmer winters. However, main problems for 
Eastern European agriculture are also of socio-economic nature. Weak economic conditions are a common feature of the countries in East Europe. This has a negative effect on agricultural production in this region in general. As a result there is a lack of real education for farmers, low labour costs and low price of agricultural products which affects the farmers income. Small farm sizes are another main limitation, but not only in Eastern European regions. Fortunately there is a trend in the considered countries (except Russia where the trend is opposite) for aggregation of small farms.

\section{Conclusions}

ADAGIO results recover a high variability of vulnerabilities, climate change impacts and potential adaptation options at the regional level for European agriculture and production systems. In order to develop recommendations for adaptation measures for decision makers at different levels therefore regional based assessments have to be applied at all levels of decision making. These assessments have not only to consider local environmental conditions, but also socioeconomic conditions which significantly affect the realibility of local adaptation measures.

Edited by: E. Koch

Reviewed by: two anonymous referees

\section{References}

European Environment Agency (EEA): Climate change: the cost of inaction and the cost of adaptation, EEA Technical report No 13/2007, EEA, Copenhague, 72 pp., 2007.

Intergovernmental panel on Climate Change (IPCC): Climate Change 2007 - The Physical Science Basis Contribution of Working Group I to the Fourth Assessment Report of the IPCC, 2007a.

Intergovernmental panel on Climate Change (IPCC): Climate Change 2007 - Impacts, Adaptation and Vulnerability Contribution of Working Group II to the Fourth Assessment Report of the IPCC, 2007b.

Mearns, L. O., Rosenzweig, C., and Goldberg, R.: Mean and variance change in climate scenarios: methods, agricultural applications, and measures of uncertainty, Clim. Change, 35, 367-396, 1997.

Meehl, G. A. and Tebaldi, C.: More intense, more frequent, and longer lasting heatwaves in the 21st Century, Science, 305, 994 997, 2004.

Orlandini, S., Nejedlik, P., Eitzinger, J., Alexandrov, V., Toulios, L., Calanca, P., Trnka, M., and Olesen, J. E.: Impacts of climate change and variability on European agriculture: results of inventory analysis in COST 734 countries, Ann. N. Y. Acad. Sci., 1146(4), 338-353, 2008.

Rowell, D. P. and Jones, R.: The causes and uncertainty of future summer drying over Europe, Clim. Dynam., 27(2-3), 281-299, 2005. 